\title{
A querela dos heróis: liderança política e ethos americano em Oliveira Lima e José Enrique Rodó
}

Fabio Muruci dos SANTOS

RESUMO: Este artigo apresenta uma análise comparativa dos primeiros textos de Oliveira Lima e José Enrique Rodó, que discutiam o uso dos EUA como modelo para o estabelecimento de uma ordem civil na América Ibérica. Propomos que ambos tencionavam estabelecer critérios para a seleção de novas elites para combater o poder dos caudilhos, mas suas agudas divergências sobre a fonte de legitimidade dessas elites tornavam opostas as respectivas avaliações da sociedade norte-americana.

PalaV Ras-ChaVe: Oliveira Lima; José Enrique Rodo; identidade americana.

A guerra de independência de Cuba, encerrada em 1898 com a decisiva intervenção norte-americana, foi um acontecimento marcante para toda uma geração de intelectuais ibero-americanos. Ela estimulou uma intensa produção de ensaios sobre as relações entre as duas Américas, seus respectivos processos de evolução histórica e o ethos cultural de cada uma. Mas a discussão não foi apenas uma reação circunstancial ao expansionismo norte-americano. Ela já estava em andamento como parte dos esforços para a superação do quadro de conflito endêmico que havia dominado a América Hispânica após a Independência. Tratava-se de estabelecer modelos de ordem social e política que substituíssem o controle dos caudilhos sobre a vida republicana local. A república norte-americana poderia fornecer modelos nesse sentido, desde que isso não implicasse uma ameaça à soberania continental. Tal dilema carregou de ambigüidade os ensaios sobre a 
identidade americana que abordaram a vida política e social nos EUA na virada para o século XX.

Entre os muitos pontos de debate enfocados, se destacava o da formação de novas elites políticas para combater o caudilhismo. Havia intensas discordâncias sobre se essas elites deveriam se alimentar das características político-culturais da tradição ibérica ou da anglo-americana. Na América Hispânica, o tema foi particularmente impulsionado pela publicação do opúsculo Ariel (1900), do uruguaio José Enrique Rodó, que alcançou projeção em todo o continente e se tornou obra de referência para várias gerações de intelectuais, até que sua aceitação viesse a cair após a Segunda Guerra Mundial. Um dos traços notáveis da recepção do "arielismo", como veio a ser chamado, foi a sua aglutinação com várias abordagens distintas da identidade ibero-americana, desde a reforma universitária de Córdoba, na Argentina de 1918, até os intelectuais do período pós-revolucionário mexicano.

A difusão do "arielismo" acompanhou de perto a onda de pensamento nacionalista que se estendeu pelo continente nas primeiras décadas do século XX, resultando em uma série de propostas para a regeneração das nacionalidades ameaçadas pelo cosmopolitismo e o materialismo, freqüentemente identificados com capitais em processo de modernização, como o Rio de Janeiro e Buenos Aires. Ao mesmo tempo, procuravam desenvolver mecanismos que integrassem os fragmentos de países deixados pelas lutas civis do século anterior. Os vários projetos regeneracionistas tinham alguns pontos em comum, como a defesa de modelos de educação que estimulassem o sentimento nacional e a recuperação da memória dos heróis pátrios. Em praticamente todos os casos, o tema central era a necessidade de constituição de comunidades nacionais em regiões que, até então, só teriam conhecido o poder de senhores regionais. Mas as vias disponíveis para estabilizar as comunidades políticas não alcançavam unanimidade. Os projetos iam desde a afirmação de regimes liberais mais efetivos até a expectativa por líderes fortes, exemplificados por Simón Bolívar, capazes de submeter os "caciques" locais. Em alguns casos, surgiram mesmo esperanças sincréticas por ditadores personalistas com "sentimento nacional”, uma variante do caudilhismo sem os traços anárquicos 
anteriores, exemplificado pelo ditador paraguaio Francia. ${ }^{2}$ Dessa forma, apesar de algumas bases em comum, não podemos falar de um "arielismo" homogêneo e sim de uma série de apropriações ecléticas, que freqüentemente resultavam em conclusões opostas.

O Brasil também apresentou a sua própria corrente "arielista" à medida que autores como Joaquim Nabuco e Eduardo Prado reagiram à implantação dos primeiros regimes militares republicanos, que ameaçavam engolfar o País nas quarteladas tidas como típicas da vida política hispano-americana. Entre eles, destacamos os escritos de Oliveira Lima por seu sistemático trabalho de comparação histórica entre as Américas ibérica e anglo-saxônica e pelos extensos comentários sobre a vida política e a sociedade dos EUA. Aqui também a abordagem "arielista" não se desenvolveu homogeneamente. Enquanto Nabuco e Prado, nos primeiros momentos da República, rejeitavam a aproximação com os EUA e seu uso como modelo, Lima demonstrou-se extremamente entusiasmado com o desenvolvimento econômico norte-americano em uma série de artigos, reunida no livro Nos Estados Unidos (1899). Sua perspectiva seria a de "melancolia com o muito que os Estados Unidos têm alcançado, e pelo pouco que nós temos relativamente feito". ${ }^{3}$ Posteriormente, Lima amenizaria a visão crítica da América Ibérica apresentada nesse livro e destacaria mais pontos positivos em comum com os EUA. Neste trabalho, porém, nos concentraremos nessa obra, que é praticamente contemporânea ao Ariel de Rodó. Nossa perspectiva é que Lima e Rodó compartilhavam importantes pontos em comum em sua abordagem geral, suficientes para designá-los com a rubrica "arielistas", mas apresentavam também divergências decisivas em vários pontos específicos. Nos concentraremos aqui nessas diferenças.

OLIVEIRA LIMA E O ETHOS AMERICANO

Oliveira Lima viveu nos Estados Unidos, como membro da legação diplomática brasileira, entre 1896 e 1900. Aquele foi um período de intensas transformações na sociedade norte-americana. A presença 
de crescentes massas de imigrantes, o constante conflito entre a polícia e trabalhadores grevistas e a formação de uma elite de grandes magnatas da indústria eram acontecimentos que pareciam mudar radicalmente as características históricas dos EUA. A sociedade formada por fazendeiros independentes, orientada por uma ética do trabalho centrada na diligência e no cumprimento de uma vocação e guiada por uma elite esclarecida de homens virtuosos parecia estar dando lugar a uma sociedade de massas cada vez mais parecida com a Europa industrial. Para muitos, estava em jogo a própria concepção do que até então era entendido como a "America”. ${ }^{4}$ É nesse quadro de mudanças que podemos incorporar os comentários de Lima sobre os EUA.

Mas o contexto ibero-americano também dava sinais de mudança à medida que alianças entre regimes de representação restrita e sistemas oligárquicos estavam dando um pouco mais de estabilidade ao quadro político conturbado da América Ibérica do século XIX. Naquele contexto, o liberalismo se tornava cada vez mais um instrumento estabilizador em torno do qual as elites locais podiam se unir para reforçar alguns mecanismos de controle e hierarquia. ${ }^{5}$ Nesse sentido, Lima procurava apreender um modelo de ordenamento social e político distinto daquele que considerava predominante na América Hispânica do século XIX, opondo o ethos anglo-americano ao ibérico. A origem da inferioridade ibero-americana estaria no predomínio de um certo tipo de "personalidade" coletiva, produzida pela Conquista espanhola e intensamente acentuada pela violenta luta pela independência. A sede do ouro, o espírito de aventura dos conquistadores e a influência da educação escolástica teriam impregnado todos os aspectos da vida local com uma tendência para o culto de personalidades extraordinárias, feitos heróicos e manifestações ostentatórias de expressão. A personalidade coletiva ibero-americana se tornou incapaz de valorizar características de liderança como equilíbrio e ponderação, o que facilitaria o trabalho para demagogos golpistas. Aí estariam incluídos os brasileiros: "nós temos, talvez como reação à estrita regra latina, um fraco visível pelo desregrado, pelo desequilibrado". ${ }^{6}$ Esse gosto pelo excessivo teria estimulado a popularidade dos caudilhos, enfraquecendo o poder das elites criollas ilustradas e fragmentando as colônias espanholas. 
A instabilidade política, porém, não deixava de estar baseada em uma efetiva forma de autoridade, só que estritamente personalista. $\mathrm{O}$ poder dos caudilhos alcançava muito de sua efetividade na relação carismática do líder com seus seguidores, o que também seria um reflexo da mentalidade ibero-americana: "um dos defeitos da mentalidade sul-americana consiste no culto supersticioso dos ídolos, no apelo à infalibilidade do mestre". ' Contra esse modelo personalista de liderança, Lima ressaltava as qualidades do modo progressivo e sincrônico da vida política norte-americana, cuja regularidade impedia explosões desordenadas e desestimulava a ação de aventureiros políticos. Nesse sentido, um modelo de liderança oposto ao dos caudilhos seria o de George Washington, cuja personalidade seria baseada no controle das emoções e na falta de ambição política pessoal:

O mérito de Washington consistia mais que tudo no comum extraordinário, se assim me posso exprimir, isto é, num conjunto de todas as virtudes de que é capaz a alma humana levadas ao seu extremo natural e perfeitamente ponderadas - e o nosso fanatismo presta somente culto ao indivíduo que apresenta uma ponta de sobre-humano, um traço espiritual exagerado, uma qualidade tornada desproporcionada e absorvente. ${ }^{8}$

A liderança de Washington seria despida de elementos de heroísmo e personalidade extraordinários, buscando exprimir sua exemplaridade através da dedicação cotidiana à causa pública e do equilíbrio das faculdades da mente, evitando que a ambição ou uma característica pessoal extremada se impusessem sobre o mecanismo da política. Ao abordar esta representação, Lima se apropriava de um dos temas centrais da cultura política norte-americana, o da importância da formação de um self adequado para o exercício da vida republicana. Já no século XVIII estavam determinados os tópicos centrais que continuariam marcando, em parte até hoje, o debate sobre a difícil relação entre um princípio econômico liberal, que vê indivíduos autônomos interagindo livremente no mercado em busca de seus interesses próprios (self-interest), e uma crença republicana que prevê que um sistema político democrático só poderia se sustentar com a participação efetiva 
de cidadãos politicamente educados e direcionados para a busca do bem coletivo.

As tentativas de encontrar um denominador comum para as duas demandas partiam do princípio de que a alta valorização do indivíduo no pensamento político-econômico liberal não precisaria resultar na indiferença pelo bem público, o que, por sua vez, implicava a formação de um tipo específico de self, cuja realização própria seria alcançada através de uma contribuição para o bem-estar coletivo. Como sincronizar o interesse próprio com esse bem comum? Uma das respostas é que o interesse próprio deveria ser estimulado dentro dos limites razoáveis da convivência e da negociação compreensiva. O comércio, campo de interação de agentes que entendem a negociação justa e a compreensão do interesse alheio como um meio superior de alcançar os seus próprios, seria o espaço mais propício para estimular o convívio civilizado. A exacerbação da vontade pessoal, ao contrário, levaria ao odiado caminho da tirania pessoal, o maior dos anátemas da cultura republicana norte-americana. Por outro lado, a interferência governamental para impor um padrão de convívio entre os cidadãos seria um inadmissível atentado à liberdade do indivíduo, inaceitável para a cultura liberal, uma recusa que distingue o republicanismo norte-americano do século XVIII dos modelos clássicos de virtude republicana. ${ }^{9}$

Como resposta ao desafio da implantação de uma ordem liberal que preservasse a virtude republicana, os ideólogos da Revolução Americana propunham a preparação de um self arduamente produzido pela educação e a autodisciplina, capaz de conter as paixões negativas inerentes ao homem - avareza, cobiça, vaidade - e direcionar o trabalho para a satisfação posterior e mais profunda dos desejos. No conjunto das faculdades da mente, a razão teria uma precedência hierárquica com relação às paixões, e seu cultivo nos homens públicos afastaria os males que geram a demagogia, o fanatismo e, como conseqüência de ambos, a luta facciosa. ${ }^{10}$ Era crença comum entre os "Pais Fundadores" que o puritanismo havia difundido profundamente as virtudes do selfcontrol entre o povo norte-americano, preparando-o para o governo republicano.

A problemática de constituir o tipo de personalidade capaz do 
exercício de uma prática republicana em um país de herança ibérica não era desconhecida no Brasil das últimas décadas do século XIX. ${ }^{11}$ Lima optou por absorver o culto a Washington como modelo de homem público que gerenciava suas paixões pelo self-control, adverso às paixões individuais que semeavam a tirania pessoal. ${ }^{12}$ Sua personalidade seria o exato oposto do selfibero-americano, instável e movido por explosões passionais. Esse perfil seria extensível a toda a cultura política dos EUA, resultando no ritmo progressivo, não-revolucionário das mudanças da história norte-americana, o qual teria criado um sistema social organizado e funcional: "nada há de mais parecido com a opinião de um Americano que a de outro Americano. É mesmo o que torna possível a exemplar disciplina política nesta enorme comunidade". ${ }^{13}$ A homogeneidade da vida nos EUA, que cinqüenta anos antes Tocqueville havia apontado como uma possível ameaça ao futuro da democracia local, é valorizada por Lima como um perfil coletivo adequado para a manutenção da democracia. O contexto sobre o qual falava, porém, havia mudado muito desde o século XVIII, o que impunha um ajuste em sua utilização do modelo norte-americano. Esse ajuste caracteriza suas posições sobre a nova "América" industrial.

Ao observar os desenvolvimentos da vida política nos EUA desde a sua independência, Lima defendeu que a evolução progressiva da democracia norte-americana teria resultado em uma relação harmônica entre as classes, já que todas compartilhariam algumas crenças comuns. Entre elas, a hegemônica seria a do self-made man, a crença no enriquecimento justo através do trabalho perseverante e do talento pessoal. Lima viveu nos EUA em uma época de crescente concentração de riqueza e ampliação do proletariado. Foi um período de intenso debate na sociedade norte-americana sobre o tema do sucesso pessoal. Muitos ensaios, revistas de aconselhamento e obras literárias populares discutiam se o poder dos grandes magnatas da indústria era um resultado justo do esforço dos mais talentosos ou, ao contrário, uma barreira contra a ascensão contínua de novos talentos.

De fato, apesar das constantes referências aos valores do trabalho e dedicação, a crença de raiz puritana de que a América era a terra de oportunidades igualitárias e que a recompensa estava assegurada para 
todos aqueles que houvessem se dedicado ao cumprimento diligente de uma vocação divina estava se corroendo. Os críticos da era industrial denunciavam que a "terra das oportunidades" havia se transformado em um mito. Outras qualidades, como a "vontade" e a "autoconfiança” pareciam expressar melhor o caminho para o sucesso que a antiga virtude da "prudência". Porém, essas qualidades traziam um componente individualista e desigual que ameaçava a mitologia igualitária norte-americana. Os entusiastas do crescimento econômico, por outro lado, respondiam que as oportunidades nunca haviam sido tão vastas, cabendo a cada um dispor das energias necessárias para trilhar o caminho do sucesso. Os vencedores seriam exemplo para os demais. ${ }^{14}$ Assim, dependendo do ângulo de avaliação, a riqueza desproporcional de um Rockfeller ou um Carnegie podia ser vista como uma prova do sucesso da igualdade de oportunidades ou como a destruição dela por um sistema concentrador e elitista. Lima tendia a optar pela primeira abordagem. Para ele, a plutocracia da indústria provava a eficiência da democracia norte-americana:

(...) uma plutocracia fundada muito mais na recompensa do esforço individual do que no mero acaso, em que o trabalhador tem autonomia e confiança e espera melhorar de condição tendo diante de si o exemplo de seu patrão ou antes do seu camarada de ontem; de uma coletividade com robustez porque tem fé, fé em Deus e fé em si própria. ${ }^{15}$

Ao adotar essa abordagem, Lima não estava apenas legitimando um arranjo específico de classes mas estava principalmente interessado na função política que essa nova elite tinha na república norte-americana. Ela seria notável por ser produto da crença homogênea no mérito da vitória por esforço próprio e autodisplicina. Assim, podia comentar: "Não há quase ricos inúteis, assim como não há quase elegantes ociosos." ${ }^{16}$ A disciplina e homogeneidade se oporiam ao gosto ibérico pela aventura e personalismo, com resultados bem mais positivos. Vitoriosa pelo talento e habilidade no mundo dos negócios, a plutocracia ganhava legitimidade para exercer um papel informal como elite dirigente através de sua influência como modelo bem-sucedido. 
Por isso, Lima não deixava de aprovar uma abordagem darwinista social sobre o papel do sucesso nas sociedades, minimizando os terríveis resultados da concorrência selvagem na Gilded Age: "Estes senões são inseparáveis, constituem a trama da eterna contenda sobre que Darwin edificou o seu sistema de filosofia natural." ${ }^{17} \mathrm{O}$ poder plutocrático seria um produto natural da seleção, permitido pelo pleno funcionamento de uma democracia estável e bem regulada. Devido à ampla difusão da crença no self-made man, o campo da concorrência econômica seria o mais propício para produzir elites com legitimidade suficiente para dar continuidade ao fantástico crescimento econômico norteamericano, sem ameaçar a regularidade da história democrática local: "Os multi-millionaires constituem em certo sentido a aristocracia desta democracia, cabendo-lhes tal nome pela situação culminante que legitimamente ocupam na hierarquia, e também pelo influxo que naturalmente deles recebe toda a vida pública." 18

Por outro lado, a ainda profunda influência da ética protestante em toda a sociedade norte-americana impediria que os vitoriosos pudessem gozar indiscriminadamente de sua riqueza e estimularia a intensa atividade filantrópica da alta elite no financiamento de universidades e museus. O amadurecimento do "experimento americano" tornava cada vez menos necessário o seu confronto com o universo ideológico europeu, que parecera indispensável quando o igualitarismo da América se definia por sua oposição aos valores hierárquicos da Europa monárquica. Na visão de Lima, a sociedade norte-americana dos anos 1890 estaria abandonando aqueles "excessos" igualitários do século XIX, agora tornados anacrônicos para uma república industrial de grandes dimensões, e recuperando uma saudável percepção dos valores hierárquicos. Para demonstrá-lo, ele descreve longamente o crescente interesse dos norte-americanos pelo seu passado, a moda das genealogias e o desenvolvimento de modos mais refinados entre a alta elite. Nesse sentido, a "república dos barões", mesmo que plutocrática, não seria uma degradação da república norte-americana criada em 1776, e sim a sua atualização e conclusão lógica para uma época de massas, mantendo o modelo de personalidade coletiva necessário para o crescimento ordenado e, ao mesmo tempo, controlando os elemen- 
tos mais igualitários que predominaram na mitologia norte-americana pré-industrial. Seria esse movimento de superação dos aspectos mais “jacobinos” da experiência americana o que haveria de mais importante como lição a ser aprendida pelos ibero-americanos.

\section{LATINISMO E AMERICANISMO EM JOSÉ ENRIQUE RODÓ}

No Ariel, de Rodó, temos uma avaliação bastante diferente dos EUA de fins do século XIX. Se Lima dizia ter escrito para informar "o que de aproveitável para nós poderia, a meu ver, resultar do exame e da confrontação" ${ }^{19}$ entre Brasil e EUA, Rodó dizia escrever um alerta contra os entusiastas do modelo norte-americano, que desejariam "uma América deslatinizada por vontade própria, sem a extorsão da conquista e logo regenerada à imagem e semelhança do arquétipo do Norte". ${ }^{20}$ No período que estamos enfocando da obra dos dois autores, Rodó tinha uma visão muito mais positiva da história e do ethos ibero-americano do que Lima. Mas, antes de entramos na análise de suas discordâncias, é preciso destacar alguns pontos em comum. Rodó também estava preocupado em buscar um modelo de ordem política que contivesse os conflitos civis constantes na América Hispânica. No período em que ele escreveu suas obras iniciais, o Uruguai passou por um ciclo de sucessivas revoltas armadas. Em carta a Miguel de Unamuno, comentou sua angústia com o estado de conturbação permanente da América Ibérica: "De mí país nada nuevo puedo decirle. La guerra civil no es cosa nueva, tratándose de pueblos donde parece haber arraigado casi como una diversión o sport nacional." ${ }^{21}$ Seu propósito era definir o tipo de cultura política mais adequado para fortalecer um sistema democrático e seletivo estável na América Hispânica, impermeável à demagogia política. Na mesma carta, conclui com um aceno de esperança nesse sentido: "veo tanta vitalidad, y tanta riqueza, y tanta fuerza almacenada en estas tierras bendecidas por la Naturaleza, que tengo por cuestión de tiempo el triunfo sobre los resabios del pasado y el predominio definitivo de los hombres de pensamiento sobre los caudillos levantiscos". 22

Nesse ponto, são esclarecedores os comentários de Angel Rama 
sobre a reação da "cidade das letras" aos primeiros momentos da modernização ibero-americana, a partir da década de 1870. Rama ressalta que a defesa dos interesses como motor do comportamento humano e o louvor do comércio como instrumento de atenuação das paixões políticas foram usados pelos liberais modernizadores como armas contra a tradição letrada ibero-americana, que controlava as universidades e se agregava ao poder desde a Independência. Essa geração buscava trazer os valores do utilitarismo para o universo ideológico ibero-americano, em confronto com os elementos ibéricos da tradição local, como a retórica legal e o idealismo filosófico.

Ao mesmo tempo, uma outra tendência dentro da "cidade das letras" reagiu a esses novos critérios de legitimação, ressaltando as virtudes do gênio pessoal e do idealismo como fundamentos do papel orientador dos intelectuais no mundo. Essa reação instigou a auto-representação dos letrados como guias potenciais da sociedade e profetas de um plano maior de realização humana, que superasse o estreito partidarismo da política comezinha e das facções locais. Fazia parte do papel autodesignado desses letrados o de incluir suas sociedades no quadro dos dramas universais de sua época. Ao mesmo tempo, como instigadores de novos horizontes, defendiam ambiciosos programas de educação que estimulassem a realização integral e as virtudes cívicas dos cidadãos. ${ }^{23}$ Rodó é explicito sobre essa função educadora, ao mesmo tempo em que expressa seu desânimo com a mediocridade do ambiente político local:

Lo innegable es que, para los que tenemos aficiones intelectuales y tendencias a una vida de pensamiento y de cultura, resultan, más que incómodas, desesperantes las condiciones (siquiera sean transitorias) de este ambiente, donde apenas hay cabida sino para la política impulsiva y anárquica que concluye por arrebatar en su vértigo a los ánimos más serenos y prevenidos. Yo no aspiro a la "torre de marfil"; me place la literatura, que, a su modo, es milicia; pero cuando se trata de luchar por ideas grandes, de educar, de redimir. ${ }^{24}$

A difusão do utilitarismo como doutrina de organização socio- 
política entrava em choque com essa proposta de orientação espiritual pela via das letras, mesmo que, no contexto ibero-americano, a oposição nunca chegasse a ser absoluta. Daí que Rodó não via a afirmação dos interesses como resposta à política pequena das lutas partidárias e facciosas, sendo de fato apenas um outro tipo de "mediocridade" avesso aos grandes propósitos. A apropriação do utilitarismo norte-americano seria a reiteração da mediocridade, apenas com outro perfil. Buscando fontes alternativas de inspiração para a regeneração, de preferência extraídas da própria experiência ibero-americana, Rodó chega mesmo a demonstrar mais simpatia pelos caudilhos, cujo heroísmo teria tido um papel histórico positivo no processo de autonomização. Mesmo ressaltando seu excessivo individualismo e ausência de sentimento nacional, Rodó destacou o vigor dos cavaleiros do interior da América como aglutinadores da força necessária para pôr em movimento um grandioso processo de mudança:

El varón de esta sociedad (...) es el llanero de Venezuela, el gaucho del Plata (...) hermosísimo tipo de desnuda entereza humana, de heroísmo natural y espontáneo, cuya genialidad bravía estaba destinada a dar una fuerza de acción avasalladora, y de carácter plástico y color, a la epopeya de cuyo seno se alzarían triunfales los destinos de América. ${ }^{25}$

Tal energia natural, porém, fora incapaz de desenvolver um engajamento na comunidade nacional, nem poderiam fazê-lo os interesses. A partir daí, Rodó se concentrou na reflexão sobre os tipos possíveis de liderança e nos valores que lhes confeririam legitimidade no quadro ibero-americano, concordando com Lima sobre a necessidade de uma elite influente, cujo exemplo desse solidez ao sistema democrático, sem abandonar o processo seletivo dos melhores: "Racionalmente concebida, a democracia admite sempre um imprescritível elemento aristocrático, que consiste em estabelecer a superioridade dos melhores, assegurando-a sobre o consentimento dos associados.”26 Mas os critérios do que deveria ser julgado exemplar e o sucesso dos EUA em alcançar estes critérios colocavam Lima e Rodó em posições praticamente opostas. Rodó não acreditava que a república norte-americana 
tivesse superado os perigos anunciados por Tocqueville mas, ao contrário, teria sucumbido definitivamente diante deles. A homogeneidade seria um traço endêmico da vida norte-americana, ainda mais acentuado a partir da industrialização.

Já na origem do ethos anglo-saxão estaria um momento fundador repressivo, que frustrou os aspectos mais criativos e belos da civilização anglo-germânica. $\mathrm{O}$ agente repressivo que criou a personalidade anglo-americana teria sido o puritanismo:

(...) a seita triste que, impondo seu espírito a partir do Parlamento inglês (...) mandou extinguir as festas que manifestassem alegria e cortar as árvores que dessem flores (...) uma sombra de morte que a Inglaterra ainda não conjurou de todo, e que perdura nas manifestações menos agradáveis de sua religiosidade e de seus costumes. ${ }^{27}$

O princípio do self-control, que para Lima teria dado base para a regularidade da sociedade norte-americana, dando sustentação ao seu duradouro sistema democrático, em Rodó aparece como um elemento banalizador do espírito criativo, especialmente o estético. A repressão dos aspectos mais lúdicos da personalidade em favor da disciplina, especialmente quando esta última é direcionada exclusivamente pelo desejo aquisitivo, teria criado nos EUA uma personalidade coletiva repetitiva e unidimensional, incapaz de abrir espaço para a exploração das diversas faculdades que compõem o espírito humano. Na percepção de Rodó, a homogeneidade seria um limitador das singularidades criadoras, princípio que aplicava tanto aos indivíduos como às sociedades: "faz parte dos deveres humanos que cada um de nós cuide e conserve zelosamente a originalidade de seu caráter pessoal". ${ }^{28}$ E somente o estímulo da singularidade poderia produzir os líderes capazes de servir de referência para a sociedade e legitimar uma ordem política democrática seletiva baseada no consentimento. Nesse sentido, seu modelo de exemplaridade seria oferecido por líderes dotados de virtudes e habilidades notáveis, mais perto do "heroísmo" ao qual o modelo de Washington se opunha, o tipo de originalidade que uma sociedade homogênea de massas, como os EUA, seria incapaz de produzir: "A oposição 
entre o regime da democracia e a alta vida do espírito é uma realidade fatal quando esse regime significa o desconhecimento das desigualdades legítimas e a substituição da fé no heroísmo — na acepção de Carlyle - por uma concepção mecânica de governo." ${ }^{29}$

A padronização da sociedade norte-americana, que já estaria anunciada desde o seu momento fundador, teria sido ainda mais acentuada pela industrialização, que subordinou toda a sociedade aos princípios da atividade mecânica, como o operário que, "com a divisão do trabalho na fábrica, é obrigado a consumir todas as energias de sua vida na invariável operação de um detalhe mecânico". ${ }^{30} \mathrm{O}$ ritmo industrial bloqueava a possibilidade do tempo ocioso, o qual seria o verdadeiro espaço para o exercício da virtude, como vista pelos "antigos": "O ócio nobre era o investimento do tempo que contrapunham, como expressão da vida superior, à atividade econômica." ${ }^{31}$

Não é à toa que Rodó cita com aprovação as críticas feitas por Herbert Spencer aos EUA durante a viagem daquele autor ao país. A escolha de Spencer é estratégica se lembrarmos que ele costumava ser lido na América Ibérica (e não só aqui) como ideólogo do competitivismo e da sociedade industrial. Mas os adversários do utilitarismo perceberam que havia também um outro Spencer, que nos últimos momentos de sua vida se mostrava cada vez mais decepcionado com os rumos da sociedade industrial e com a crescente onda imperialista que ameaçava submergir o mundo na barbárie militar. Um dos fracassos das sociedades industriais seria exatamente a sua incapacidade de propiciar um modelo de educação que contemplasse todas as faculdades do indivíduo, uma crítica perfeitamente assimilável pelo ideário dos "arielistas". Assim, Spencer criticou o regime de trabalho industrial e a obsessão pelo ganho como ameaças ao futuro da democracia norteamericana por transferir o controle da política aos bosses, donos dos currais eleitorais. A crítica spenceriana ao utilitarismo se aproxima muito da própria linguagem rodoniana: "The primary use of knowledge is for such guidance of conduct under all circumstances as shall make living complete. All other uses of knowledge are secondary." ${ }^{32} \mathrm{O}$ Spencer selecionado por Rodó recusava a concepção utilitarista do tra- 
balho como fim último da vida, demandando dos norte-americanos "a revised ideal of life".33

Presos a um regime de autodisciplina e homogeneidade, os norte-americanos seriam incapazes de encontrar tempo livre para a atividade espiritual desinteressada. Da mesma forma que Lima usava um patriarca norte-americano para exemplificar um modelo positivo de self, Rodó usará um dos santos-padroeiros de muitos americanistas na América Ibérica, Benjamim Franklin, como exemplo das perversões do self puritano, quando tornado modelo de comportamento social:

A mais elevada cúspide de sua moral é a de Franklin: uma filosofia da conduta que encontra seu termo no medíocre da honestidade, na utilidade da prudência, de cujo seio jamais surgirá a santidade nem o heroísmo. ${ }^{34}$

Franklin foi um dos defensores do interesse como uma virtude possível na medida em que estimulasse o desejo de contribuir para o bem comum, como no caso do desejo de "estima" pelo trabalho realizado. Tanto os preceitos morais como os religiosos poderiam alcançar valor por sua "utilidade" social, mesmo que não estivessem reduzidos a ela. ${ }^{35}$ Este elemento utilitário, somado a um modelo de self desapaixonado e autodisciplinar, seria um padrão capaz de dar constância ao mundo, uma característica altamente valorizada pelos defensores setecentistas das "paixões calmas" mas que se tornaria um dos principais alvos da crítica romântica ao caráter mesquinho e sem glória do mundo capitalista. ${ }^{36}$ É nessa perspectiva que podemos localizar certa melancolia nostálgica rodoniana pela perda do ethos de glória causado pelo advento da modernidade, visível em sua admiração por Garibaldi:

Una de las últimas y más radiantes apariciones de lo heroico en la historia. Nos asombra aún más, en el tiempo en que vivimos, por lo que se aparta y disuena de las condiciones de la realidad circunstante. El pasado siglo, que empezó entre los fuegos de la epopeya napoleónica, es rico de esos formidables nombres en que Carlyle y Emerson cifraron su filosofía de la historia. El nuestro empieza como en un vago estupor, como en una fría reserva. ${ }^{37}$ 
Garibaldi era um dos modelos rodonianos de líder heróico para a sonhada regeneração do universo latino. Diferente de Oliveira Lima, os elementos de heroicidade e idealismo da cultura de origem latina eram valorizados por Rodó desde seus primeiros escritos como uma fonte ainda vigorosa de inspiração cultural. A regeneração ibero-americana, em sua opinião, deveria começar com a revitalização dos componentes idealistas da civilização latina, não apenas a Ibéria mas, igualmente, a França e a Itália. A seguir, propunha a mobilização dos intelectuais para estreitar os laços culturais entre os países latinos da Europa e os hispano-americanos. Todo o milenar arcabouço do idealismo latino, devidamente ajustado ao mundo contemporâneo, seria uma fonte de exemplaridade muito mais estimulante para os novos líderes ibero-americanos do que o estreito utilitarismo anglo-americano e sua concepção mecânica da história.

$\mathrm{Na}$ escolha dos respectivos "heróis", ou poderíamos dizer "nãoherói" no caso do Washington visto por Lima, podemos divisar alguns dos princípios que orientavam as respectivas concepções de liderança. Enquanto Lima considerava o sistema de seleção baseado no sucesso econômico dos self-made men (desde que devidamente educados para o exercício da virtude política) como o mais bem-sucedido em produzir lideranças capazes de equilibrar democracia com ordem política, Rodó negava que o fator econômico fosse plenamente compatível com a seleção de elites virtuosas. De fato, como podemos concluir por seus comentários sobre o ócio aristocrático, os "barões" da indústria norteamericana seriam os modelos mais adversos possíveis ao seu critério de liderança. Seguindo uma versão idealizada das aristocracias antigas, especialmente as da pólis grega, seria exatamente no momento em que a atividade econômica cessa que o homem teria condições para se entregar ao trabalho pelo bem público, movido apenas pela virtude desinteressada. A atividade econômica incessante, ao contrário, enfraqueceria as bases da virtude desinteressada que sustentam uma república: "a escola da prosperidade material (...) sempre será uma rude prova para a austeridade das repúblicas”. ${ }^{38}$ No quadro da vida norte-americana da era industrial nem os magnatas, envolvidos na competição darwinista brutal, nem os trabalhadores, submetidos ao regime 
mecânico da linha de produção, poderiam encontrar condições para esse ócio humanizador.

O regime de predomínio absoluto do homo oeconomicus estaria minando a virtude como fator de legitimação da república norte-americana: "O valor cívico, a velha virtude dos Hamilton, é uma lâmina de aço que se oxida, cada dia mais esquecida, entre as teias de aranha das tradições" ${ }^{39}$. Nesse sentido, Rodó conclui que o modelo de República construído pelos "Pais Fundadores" norte-americanos estaria dando claros sinais de deterioração na medida em que a plutocracia concentrava mais poder:

(...) a preocupação exclusiva com o engrandecimento material - nume daquela civilização - impõe assim a lógica de seus resultados na vida política, bem como em todas as ordens de atividade, conferindo o primeiro lugar ao struggle-for-life ousado e astuto, convertido pela brutal eficácia de seu esforço na suprema personificação da energia nacional. ${ }^{40}$

Nesse sentido, as posições de Lima e Rodó sobre a vigência do modelo republicano norte-americano, em suas primeiras obras, eram praticamente opostas. Para Lima, o americanismo seria um caminho para a atualização do universo ibero-americano, pondo em relevo as similaridades potenciais a serem exploradas no futuro. Em Rodó, ao contrário, a utopia da regeneração ibero-americana, ou mais apropriadamente "latino-americana", se desenvolveria, pelo menos provisoriamente, pela negação do americanismo. Em ambos, a legitimidade hierárquica das novas elites ibero-americanas deveria ser baseada no consentimento e no exemplo em vez da força ou de direitos adquiridos. Mas as respectivas concepções sobre as fontes de legitimidade eram bastante diferentes, expressando duas das concepções de República presentes no debate ibero-americano do fim do século XIX.

SANTOS, F. M. dos. The battle of the heroes. Political leadership and American identity in Oliveira Lima and José Enrique Rodó. História. São Paulo, v. 22, n.2, pp. 79-98, 2003. 
A BSTRACT: This article presents a comparative analysis of the Oliveira Lima and José Enrique Rodó"s first works about the United States and the possibility of using them as a model for a Latin American civil order. We argue that they intended to determine the values with which could be selected new elites to fight against the caudillos but the sharp disagreement between them on the sources of legitimacy of those elites made opposite their respective evaluations on the North American society.

KEYWORDs: Oliveira Lima; José Enrique Rodo; American identity.

\section{NOTAS}

${ }^{1}$ Doutorando no Programa de Pós-Graduação em História - UFRJ - CEP 20051070 - Rio de Janeiro - RJ. A pesquisa contou com bolsa do CNPq e auxílio da CAPES para visita a Oliveira Lima Library (Washington DC).

${ }^{2}$ VALDÉS, E. D. El pensamiento latinoamericano en el siglo XX: entre la modernización y la identidad. Buenos Aires: Centro de Investigaciones Diego Barros Arana, 2000.

${ }^{3}$ LIMA, O. Nos Estados Unidos (Impressões políticas e sociais). Leipzig: F. A. Brockaus, 1899, p. 17.

${ }^{4}$ TRACHTENBERG, A. The incorporation of America. Nova York: Hill and Wang, 1982, cap. 3.

${ }^{5}$ PAMPLONA, M. A. "Una perspectiva "Arielista" entre los hombres públicos brasilenõs de fin de siglo: Joaquim Nabuco y Oliveira Lima”. In: Estados Unidos desde América Latina: sociedad, política y cultura. Cidad del México: Colegio de México, 1995.

${ }^{6}$ LIMA, O. Nos Estados Unidos, p. 11.

7 _ Impressões da América Espanhola (1904-1906). Rio de Janeiro: José Olympio, 1953, p. 133.

8 _. Nos Estados Unidos, p. 11.

${ }^{9}$ VETTERLI, R.; BRYNER, G. In search of the republic: public virtue and the roots of American government. Lanham: Roman \& Littlefield, 1996.

${ }^{10}$ HOWE, D. W. Making the American self: Jonathan Edwards to Abraham Lincoln. Cambridge; Londres: Harvard University Press, 1997. 
${ }^{11}$ CARVALHO, J. M. de. A formação das almas. São Paulo: Companhia das Letras, 1990, cap. 1.

${ }^{12}$ SCHWARTZ, B. The character of Washington: a study in Republican culture. In: American Quarterly, Baltimore: The Johns Hopkins University Press, v. 38, noㅡ 2, pp. 202-222, 1986.

${ }^{13}$ LIMA, O. Nos Estados Unidos, p. 112.

${ }^{14}$ CAWELTI, J. G. Apostles of the self-made man. Changing concepts of success in America. Chicago: The University of Chicago Press, 1972.

${ }^{15}$ LIMA, O. Nos Estados Unidos, p. 169.

${ }^{16}$ Idem, p. 106.

${ }^{17}$ Idem, p. 107.

${ }^{18}$ Idem, p. 198.

${ }^{19}$ Idem, p 17.

${ }^{20}$ RODÓ, J. E. Ariel. Tradução de Denise Bottmann. Campinas: Unicamp, 1991, p. 70.

${ }^{21}$ Carta datada de 20 de março de 1904. Apud: RODÓ, J. E. Correspondencia. In: Obras Completas. Madrid: Aguilar, 1967, p. 1317. Nas citações de Ariel decidi usar a tradução de Denise Bottmann, de fácil acesso no Brasil. Nos outros textos de Rodó, preferi manter o original em espanhol.

${ }^{22}$ Idem, p. 1317-8.

${ }^{23}$ RAMA, A. A cidade das letras. São Paulo: Brasiliense, 1985.

${ }^{24}$ RODÓ, J. E. Op. cit., p. 1318.

${ }^{25}$ _. Bolivar. In: Obras Completas. Madrid: Aguilar, 1967, p. 551-552.

${ }^{26}$ . Ariel, p. 64.

${ }^{27}$ Idem, p. 43.

${ }^{28}$ Idem, p. 72.

${ }^{29}$ Idem, p. 55.

${ }^{30}$ Idem, p. 29.

${ }^{31}$ Idem, p. 36.

${ }^{32}$ SPENCER, H. Herbert Spencer on the Americans and the Americans on Herbert Spencer. YOUMANS, E. L. (Org.). New York: Arno Press, 1973, p. 32.

${ }^{33}$ Idem.

${ }^{34}$ RODÓ, J. E. Ariel, p. 86. 
${ }^{35}$ HOWE, D. W. Op. cit.

${ }^{36}$ HIRSCHMAN, A. O. As paixões e os interesses. São Paulo: Paz e Terra, 1979.

${ }^{37}$ RODÓ, J. E. Garibaldi. In: Obras Completas. Madrid: Aguilar, 1967, p. 534, grifo no original.

38 . Ariel, p. 86.

${ }^{39}$ Idem, p. 87.

${ }^{40}$ Idem, p. 88.

Artigo recebido em 06/2003, aprovado em 08/2003. 